\title{
Research Article \\ Exploring the Attitudes of Students to Distance Learning during Covid-19 in Morocco: The Case of Students of English Studies at Faculty of Letters in Beni-Mellal
}

\author{
Said Elmouhtarim \\ Sultan Moulay Slimane University, FLH, Beni-Mellal, Marocco
}

\begin{abstract}
Accompanying the outbreak of Covid-19 pandemic, there has been an unprecedented practice in education worldwide, resorting to distance learning (DL) at large. Morocco is no exception. Having continued our teaching practice through this new orientation in the second semester of the academic year 2019-2020, we thought that this experience was worth reflecting on. This study aims at exploring the attitudes of the students to distance learning. The method of this research is a quantitative study where a questionnaire was administered to a target population of 160 students belonging to the department of English studies at the Faculty of Letters in Beni-Mellal, Morocco. The findings we obtained from a questionnaire addressed to 160 students at the Faculty of Letters in Beni-Mellal revealed that the attitudes of students towards distance learning are generally positive. Still, it must be admitted that these findings also showed that there are some challenges facing a sound implementation of this new orientation in teaching, which necessitates some requirements both in terms of digital resources and digital pedagogy to reach efficiency in the future.
\end{abstract}

Keywords: Attitudes; distance learning; Covid-19; digital pedagogy; efficiency.

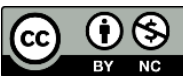

This is an open access article under the CC-BY-NC license.

\section{INTRODUCTION}

With the outbreak of Covid-19 and the accompanying pandemic, the educational field witnessed an unprecedented crisis. Schools and universities were closed as a protective measure to avoid the risk of having the disease spread among the huge number of students worldwide. To manage this crisis, distance learning (DL) was adopted. Entitled Exploring the Attitudes of students to distance learning during Covid-19 in Morocco: The case of students of English studies at Faculty of Letters in BeniMellal, the current research-based paper aims at addressing an issue related to distance learning. Actually, there is a gap in research related to this mode of education, at least in Morocco. To limit the scope of this study, we will be concerned mainly with the attitudes of students to distance learning. The paper includes the following parts: a review of literature is presented first, starting with a section on Covid-19 and its impact on education. Then a historical view on distance education and its development is presented, showing its advantages and its disadvantages. This first part also sheds light on the requirements of efficient distance learning, both in terms of digital resources and digital pedagogy. After this, we proceed to the presentation of the second part of the current study (the research methodology), starting with the statement of the research problem, the research questions and the research tools. The third part of this article is devoted to the discussion of the findings and providing answers to the research questions of the study. The paper concludes by stressing the fact that distance learning is emerging as a new orientation in the educational scene though it is facing some challenges. What is needed is to create a favourable climate for its implementation, taking into account its pedagogical and technical requirements. From the preliminary research, many articles explored the impact of Covid-19 through education, e.g. Marinoni, G., Van't Land, H., \& Jensen, T. (2020); Dwivedi, Y. K., Hughes, D. L., Coombs, C., Constantiou, I., Duan, Y., Edwards, J. S., \& Upadhyay, N. (2020); Burgess, S., \& Sievertsen, H. H. (2020) stated that the disruption in the current situation is undeniable and increase inequality of learning opportunities. The efforts put in place to prevent a void 
academic year, to ensure future planning despite the high degree of uncertainty, with the risk of decreasing private and potentially also public funding, demonstrate the incredible amount of pressure on higher education institutions to cope during the current crisis and at the same time their resilience and creativity. This research tries to explore a similar situation that happened all over the world but precisely only elucidate in Marocco case.

\section{LITERATURE REVIEW}

\section{$A$ view on Covid-19 and its impact on education}

Coronavirus influenced not only health but also all aspects of society worldwide, especially education. Concerning the impact of Corona Virus on the educational sector, it was clear that with the outbreak of this pandemic, the world started undergoing one of the greatest threats ever. The threat to global education declared a big educational crisis starting from March 2020. The Covid 19 pandemic pushed governments to close down schools and universities as a proactive measure, which was followed by partial lockdowns and a health emergency state. Students started experiencing a global learning crisis because they were forced to stay at home. Consequently, learning the fundamental skills needed for life and the process of socializing, which normally take place at schools and through interaction with peers, was blocked.

Managing the crisis was a big problem for the countries which were attacked by this pandemic. It was a multi-fold crisis because the governments had to manage the health of people and cure those who suffered from the effects of Corona virus. They also had to manage the pace of the economy, at least, to make sure the basic needs were available. In addition to this, it was also a priority to manage the educational sector to ensure pedagogical continuity and to save the academic year. There was no choice from resorting to distance teaching and learning. This new mode of teaching was familiar in some educational systems, but it was a new experience in some countries, including Morocco.

\section{Distance learning as an emerging model of education $A$ view on distance learning}

Distance education or distance learning is that type of education in which the delivery of instruction is not done in the classical way, which involves face to face interaction between the two main agents of education: the teacher and the students. According to Keegan (2002, p. 20), distance education can be summarized as "teaching and learning in which learning normally occurs in a different place from teaching". The principal feature of this mode of education is that students are not physically present in a traditional setting such as the classroom. The source of information and the learners are separated by time and distance or both. Distance education is not a new practice.

Today distance education has developed so much, especially with the emergence of Distance e-Learning or DeL, which is the combination of distance education and e-Learning. The latter type of education is characterized by extensive use of Information and Communication Technology (ICT) in the delivery of education and instruction and the use of synchronous and asynchronous online communication in an interactive learning environment or virtual communities, instead of a physical classroom, to bridge the gap in temporal or spatial constraints (Felicia, 2015). It, thus, combines the strengths and advantages of distance education and e-Learning.

Briefly, as a result of the tremendous development of third-generation distance learning systems that include interactive videos, emails, and World Wide Web technologies, distance learning has been redefined to include teacher student interaction (Katz, 1998, 2000; Trentin, (1997), taking different forms such as:

a) Web conferencing refers to a service that allows conferencing events to be shared with remote locations. These events are sometimes referred to as webinars or interactive conferences, and 
online workshops. This service allows real-time point-to-point communication as well as multicast communication from one sender to many receivers. It has the possibility of textbased messages, voice and video chat to be shared simultaneously in different geographical locations. This mode has been used a lot during Covid-19 to share teaching materials in different domains.

b) Educational television: This consists of the use of television programs in the field of distance education. It may be in the form of individual television programs or official special channels. This was also used a lot during Covid-19 to share lessons with the students.

c) Live streaming which refers to content delivered live over the Internet. It requires a camera for the media, an encoder to digitize the content, a media publisher, and a content delivery network to distribute and deliver the content.

A further point needs to be included when dealing with DL, and this concerns its approaches. In this respect, two approaches can be mentioned: the synchronous approach and the asynchronous one. The synchronous model is used to describe forms of education and learning that occur at the same time but not in the same place. It has a live nature which makes it different from asynchronous distance learning (Hrastinski, 2008). Synchronous learning has a number of key benefits when compared to other distance learning delivery models. One of these benefits is structured learning. The group involved in learning is required to participate simultaneously. Clear guidance on how the work needs to be done is provided, and the pace of learning is controlled. Every member of the group is kept on task. Another benefit is related to interaction. In this respect, synchronous learning allows the entire learning group to interact in real-time, which offers solutions to the sense of isolation that can come from distance learning models that do not offer this kind of interaction, and this can be beneficial for improving student engagement and maintaining interest.

The asynchronous model, on the other hand, is a type of learning in which the student and the teacher are not directly communicating in real-time. The instructor delivers the lessons at a time which is different from the time in which the learner receives them. It relies on pre-recorded e-learning platforms and downloadable materials. Among its strong points, there is accessibility and practicality. Still, it has some weak points related to limited contact with the instructor and lack of instant feedback. Consequently, for better delivery of the courses, DL systems have to use both the synchronous and the asynchronous modes (Kamal and Sultana, 2000).

\section{Advantages and disadvantages of distance learning}

Distance learning, as a new model used in education, has some advantages and some disadvantages. The advantages of distance learning consist of flexibility which offers numerous choices and materials that students can have access to whenever and wherever they are and at their own convenience. For students, it means easier access to learning, greater convenience in choosing where to study, a wider variety of credentials to aim for and more autonomy in scheduling their lives" (Daniel, 2016b, p.2). Traditional styles of classroom education can never offer such flexibility. Another advantage mentioned about using one's pace of study which students can set their own pace of study. The use of online education enables students to work at their own pace in many circumstances because the regulations are not very rigid. The next advantages are ease in accessing resources and motivation which especially the asynchronous mode, there is an ease in having access to the assigned materials without restrictions. Besides, these resources are motivating and appeal to the type of today learners, the so-called digital learners. Responsibility also includes the advantages of distance learning, as well as students take some responsibility for their learning because distance learning boosts self-study, which is centered on studying without direct supervision or attendance in a classroom. Concerning 
responsibility, distance learning requires some competencies on the part of the learner (Birch, 2001), such as operational competence and competencies related to the efficient use of ICT tools for learning, communicating, collaborating and self-direction. The last advantage is autonomy which is considered an ultimate goal of education. Students find themselves in a situation where they need to rely on themselves in reading, thinking about and analyzing the materials they continuously receive from their teachers to make the most of them.

Despite all these advantages, the disadvantages of distance learning cannot be ignored as well; they will be mentioned later in the article. The most primary disadvantages about problems related to maintaining motivation. For many students, not having scheduled lessons related to a particular setting such as the classrooms makes it difficult to be motivated all the time or to maintain one's motivation, especially the one that comes from within. Another point of view is about communication problems which were one facet of communication problems that emerge with distance learning is related to the difficulty of staying in direct contact with the instructors and getting immediate feedback. In face-to-face teaching, if the learners have problems with understanding the courses, they can always interact with their teachers, who respond immediately. In distance learning, there is also the possibility of contacting the teachers through emails and other means, but such contact is not as effective as the direct one. The absence of immediate feedback may have some negative effects on the process of learning. According to Nkingwa $(2013$, p.25) stated that students often feel a bit disconnected and isolated when they do not get feedback in time. The next disadvantage is difficulty interacting with peers because there is no possibility to have that real contact with peers. Group discussions done through the internet are less interactive. There is no possibility to work in groups and converse in the same way as in real classrooms. Above all, in distance learning, students tend to feel isolated from peers, and it is difficult to build genuine relationships. Technical problems are the next barrier of distance learning because it requires some technological equipment ranging from a reliable source of electricity, owning some devices such as a computer, a tablet or a mobile and a reliable internet connection.

\section{Requirements of distance learning}

The main requirements of efficient distance learning can be illustrated in the following pyramid proposed by Hampel and Stickler (2005). This pyramid consists of seven categories of skills for teaching languages online, beginning with more general skills of working with technology, its constraints and possibilities, moving on to the social skills of community building, with the highest level comprising skills in teaching languages creatively and developing a personal teaching style online.

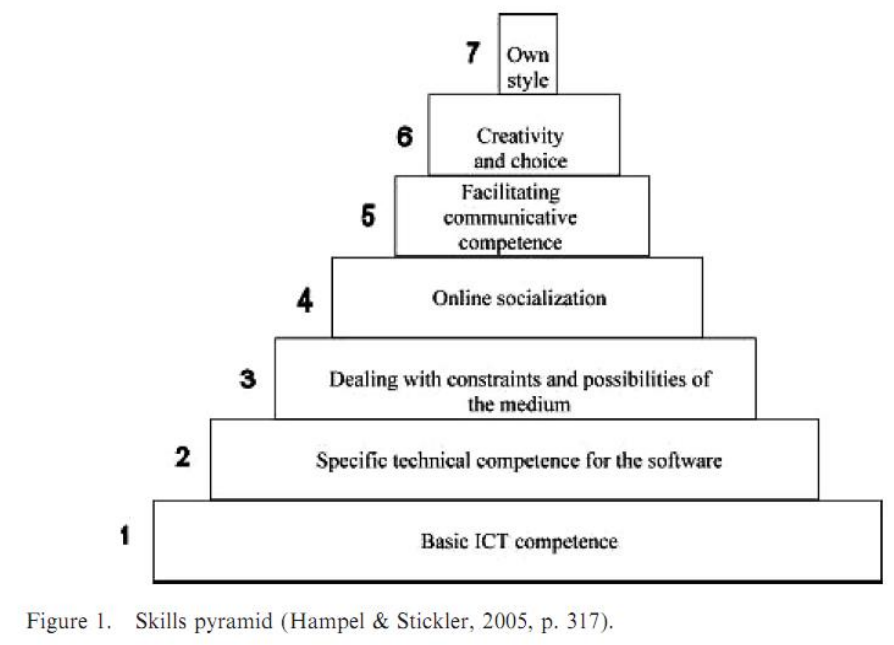


According to Hampel and Stickler (2005), teaching language online requires some additional skills that are different from those used to teach language in face-to-face situations.

Based on their years of teaching languages synchronously in an online environment and experience in the training of online tutors, Hampel and Stickler (2005) identified the key competencies needed to teach online, as illustrated in Figure 1. Compton (2009) added that these competencies range from lower-level skills (e.g. basic ICT competence, specific technical and software competence and awareness of constraints and possibilities) to higher-level skills (e.g. online socialization, facilitation of communicative competence as well as creativity, choice and developing one's own style). From this, we infer that distance learning, especially in its developed form, distance e-learning (Del) requires some basics in using educational technology. But, this is never sufficient in the educational field because issues related to pedagogy, being able to communicate effectively and contributing to the socialization process of students are always of great importance. After all, social relationships, peerto-peer interactions and developing social skills are crucial to develop at any educational level.

\section{RESEARCH METHOD}

Having participated in distance learning during Covid-19, we got the idea that this experience needed some reflection and research. So, we decided to conduct this study to explore the attitudes of students in Morocco to distance learning, taking into account the claims of different literature about this type of teaching and its requirements. The coming sections shed light on this study.

\section{Statement of the research problem and the research questions}

The aim of the current study is to explore the attitudes of one agent most concerned with education (the students) to distance learning to see whether these attitudes are positive or negative and whether there is a climate for the implementation of distance learning in the Moroccan context. To give orientation on this study, three related research questions were put forward, and they were formulated as the following:

1. What are the attitudes of students towards distance learning?

2. Does the implementation of DL in Morocco face any challenges?

3. To what extent is DL efficient, as a new orientation, to manage the crisis in education in Morocco that started with the outbreak of Covid-19?

\section{Research Administration}

In order to get data related to the present study with a special focus on DL, the tool that was used was a questionnaire, which was administered to a target population of 160 students belonging to the department of English studies at the Faculty of Letters in Beni-Mellal. This target population included 86 male and 74 female students from Semester 2, Semester 4 and semester 6. All of them underwent the experience of DL for the first time during Covid-19. The data we got from this questionnaire was classified and transformed into graphs and statistics using Excel Program. The analysis of data was conducted according to some variables related to the use of DL, such as flexibility, ease of use, convenience, motivation, autonomy, satisfaction and parameters related to the technical side. We were interested in a mixed approach methodology that combines both the quantitative and the qualitative approaches. The quantitative side was justified by our intention to have some statistics related to the study. The qualitative aspect, on the other hand, was justified because deep understanding and interpretation of the results were also important in this study. This was reached by including items in the questionnaire asking the participants to give reasons for their answers. 


\section{FINDINGS AND DISCUSSIONS}

\section{The development of Distance Learning during Covid-19 in Morocco}

With Corona virus pandemic, schools and universities were closed in almost all countries. However, education was not stopped completely. There was an urgent need for measures to manage the crisis. Governments resorted to distance education to ensure that students are not disconnected from the educational process. Different technological tools, such as television, online platforms, the Internet and mobile applications, were used. A lot of countries, including Morocco, decided to launch distance education immediately after the closure of the schools. In this respect, teachers were expected to support students academically and to be engaged in distance education to ensure pedagogical continuity and to save the academic year. It must be stressed again that there was no alternative from resorting to distance learning as a new orientation in Morocco. Different platforms were accessible such as Microsoft Teams, Zoom, Google Classroom, Google Meet, Moodle, Digital resources prepared by teachers and uploaded on some websites.

All these facilities prove that distance learning has developed rapidly in a short period of time. Some statistics from the Faculty of Letters and Humanities in Beni-Mellal show this. Up to May 3rd, 2020 -for a period of fewer than two months, a lot of materials were available for the students through distance learning. These are shown in the following list:

Table 1. Available Material during Distance Learning (DL)

\begin{tabular}{lll}
\hline No & \multicolumn{1}{c}{ Media } & \multicolumn{1}{c}{ Quantity } \\
\hline 1. & Moodle and in the Website of Faculty of Letters and Humanities in & 760 pedagogical support \\
& Beni-Mellal. & \\
2 & Youtube & 90 lectures \\
3 & Microsoft Teams & 60 live lectures \\
4 & Recorded by the Department of History at Faculty of Letters and & 49 lectures \\
& Humanities in Beni-Mellal and were broadcast on TV channels & \\
\hline
\end{tabular}

These statistics show that 35700 visits from the students to the website and the digital resources of this Faculty and show that a lot of work was done by teachers and the administrative staff. However, the attitudes of students need to be investigated to see the extent to which distance learning is gaining or losing acceptance among Moroccan students. This was the rationale behind conducting the current study.

\section{The attitudes of the participants to $D L$}

A close analysis of the data we got from the questionnaire we administered to the students, as shown in Table 1, reveals that most of the participants, regardless of their gender, reacted positively to some items related to the benefits of distance learning.

Table 2. Attitudes of the participants to DL

\begin{tabular}{lcccc}
\hline \multicolumn{1}{c}{ Items } & Yes & Percentage & No & Percentage \\
\hline DL involves flexibility in time & 135 & 84.38 & 25 & 15.62 \\
With DL, there is easy access to resources & 130 & 81.25 & 30 & 18.75 \\
$\begin{array}{l}\text { With DL, consulting resources is done at one's own } \\
\text { convenience }\end{array}$ & 135 & 84.38 & 25 & 15.62 \\
$\begin{array}{l}\text { DL motivates the students and appeals to digital } \\
\text { learners }\end{array}$ & 151 & 94.38 & 9 & 5.62 \\
With DL, students take some responsibility for their & 152 & 95 & 8 & 5 \\
learning & 152 & 95 & 8 & 5 \\
DL boosts self-study & & & 5
\end{tabular}


DL encourages autonomy

Getting knowledge through DL is satisfactory
157

150
98.12

93.75
1.88

6.25

According to the statistics shown in Table 1, the majority of the participants have positive attitudes to some aspects related to distance learning. 135 of the participants representing $84.38 \%$ admit that distance learning is flexible in terms of time and consulting resources at one's convenience, unlike face-to-face teaching, which has a fixed scheduled time. Related to this, 130 participants representing $81.25 \%$ of the respondents, add that DL involves ease in consulting resources. Besides, $94.38 \%$ of the respondents believe that DL is motivating and appeals to the digital learners of today. Moreover, 95\% of the participants think that with DL, students take some responsibility for their learning. Also, it is worth noting that $95 \%$ and $98.12 \%$ of the respondents put forward that DL boosts self-study and encourages autonomy, respectively. What is even interesting is that 150 of the participants representing $93.75 \%$ declare that getting knowledge through DL is satisfactory.

\section{The challenges facing distance learning and further attitudes}

Another facet related to the attitudes of students to DL concerns the challenges that hinder a sound implementation of DL. Graph 1 shows this clearly.

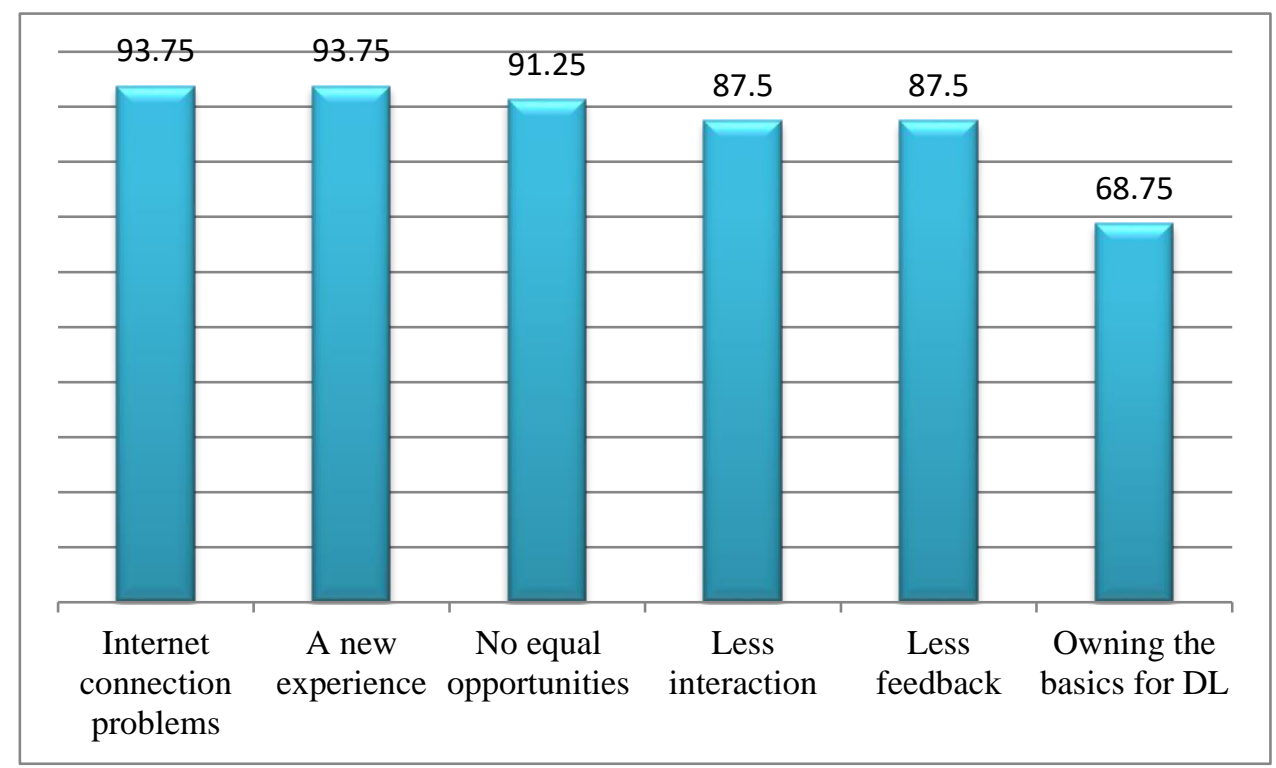

Graph 1: Challenges related to DL: The perspective of the students

According to the respondents, the most striking challenge facing distance learning is related to the technical side. 150 respondents representing $93.75 \%$ of the participants stress that problems related to Internet connection and to the fact that distance learning is a new experience for the students act as obstacles towards the implementation of DL. Besides, 146 of the participants representing $91.25 \%$, claim that with DL there are no equal opportunities. According to them, not all students have a stable Internet connection. This has another consequence directly linked to the absence of equal opportunities in getting knowledge. One more finding is that 140 of the respondents representing $87.5 \%$ put forward that with distance learning, there is less interaction and less feedback compared to face to face teaching. What is even striking is that more than half of the participants $68.75 \%$ revealed that they do not own the basics even for asynchronous distance learning such as a computer or a tablet. It should be mentioned again that asynchronous distance learning is that type of DL that does not necessitate a continuous Internet connection and where materials once downloaded can be accessed offline. Briefly, it should be noted down that although the majority of the participants 
in this study have positive attitudes to DL, they admit that there are some challenges facing this new orientation in teaching and learning.

Now to answer the research questions of the current study, we stress again that the majority of the participants hold positive attitudes to embrace DL as a new strategy to manage the crisis in education that accompanied Covid-19 pandemic and lockdown. Once again, the majority of the respondents agree that DL has a lot of benefits, including flexibility, ease and convenience in accessing resources, motivation, responsibility and autonomy. These findings provide answers to the first question. However, the challenges that face DL, especially the ones associated with the technical side, such as Internet connection problems, owning the basics of DL, no equal opportunities in accessing knowledge, less feedback, cannot be ignored. These challenges provide answers to the second research question of this study. Concerning the third related question, which is about the extent to which distance learning is efficient, as a new orientation, to manage the crisis in education that started with the outbreak of Covid-19, the answers to this question are closely linked to those of the first question. DL is, to some extent, efficient. Taking into consideration of its benefits. The ministry of education and the universities in Morocco have succeeded in managing the crisis and saving the academic year through DL. Besides, some statistics from the current study have revealed that DL is efficient, especially the statistics related to motivation and satisfaction of the students with the knowledge they got through DL. $94.38 \%$ and $93.75 \%$ of the participants showed such motivation and satisfaction, respectively. This is an important finding that can be invested in in the future as far as DL, as an emerging orientation in education in Morocco, is concerned.

\section{CONCLUSION}

DL is a promising orientation in education, especially at the university level. It is an innovative pedagogy involving new ways of teaching and learning. However, some requirements should be met to make it efficient, especially those requirements related to the technical side, such as Internet connection and the availability of the logistics for the students. The implication here is that DL has become a reality that cannot be overlooked when dealing with the new generation of students; the socalled digital learners. We should also bear in mind the emerging digital pedagogy accompanying DL, which is about using digital tools thoughtfully, interactively and meaningfully with an added value to reach quality education. Additionally, we should allow some time for the process of learning in DL that involves reception, reflection, retention, reaction and giving feedback. The last thing to admit is that we have gained a lot from adopting DL to manage the educational crisis that accompanied Covid-19 pandemic. Now the policymakers, the teachers, the students and the parents are aware of DL. The attitudes of the students are what concerned us most in this study, whose findings have shown that these attitudes are to a great extent positive. This is a variable that should be invested in to improve the quality of DL in the future.

\section{REFERENCES}

A Case of the Open University of Tanzania- Tanga Regional Centre. A dissertation and Achievement of College Students. In G. Davies (Ed.), 31(4). Retrieved from https://er.educause.edu/articles/2008/11/asynchronous-and-Synchronouse-learning Belmont, CA: Wadsworth. ISBN 0-534-50688-7.

Birch, D. (2001). E-Learner Competencies. Retrieved from: http://sdl_demo.s3.amazonaws.com/89/www/24328/1/1.pdf

Burgess, S., \& Sievertsen, H. H. (2020). Schools, skills, and learning: The impact of COVID-19 on education. VoxEu. org, 1(2). 
Compton, L. (2009). Preparing Language Teachers to Teach Language Online: a look at Computer Society (OCG), Vienna.

Daniel, J. S. (2016a). Making Sense of Blended Learning: Treasuring an Older Tradition

Daniel, J. S. (2016b). Making Sense of Flexibility as a Defining Element of Online Learning.

Di Pietro, G., Biagi, F., Costa, P., Karpiński, Z., \& Mazza, J. (2020). The likely impact of COVID-19 on education: Reflections based on the existing literature and recent international datasets (Vol. 30275). Publications Office of the European Union.

Distance Education of the Open University of Tanzania.

Distance Education. Bangladesh, Bangladesh University Press.

Felicia, K. O. (2015). Effect of Emotion on Distance e-Learning — the Fear of Guide. SAGE Publications, Inc.

Hampel, R. \& Stickler, U. (2005).New skills for new Classrooms: Training Tutors to Innovation in Language Learning and Teaching Vol. 1, No.

1. Journal of Computer Assisted Learning 13: 261-270.

Hrastinski, S. (2008). Asynchronous and Synchronous E-Learning. EDUCAUSE Quarterly, Journal of Computer Assisted Learning, 18: 2-9.

Kamal, M. Z. \& Sultana, S. A. (2000). Barriers to Development in Open Leaning and

Katz, Y.J. (1998). The Relationship between Distance Learning Methods and Satisfaction

Katz, Y.J. (2000).The Comparative Suitability of three ICT Distance Learning Methodologies for College Level Instruction. Educational Media International, 37 (1): 25-30.

Katz, Y.J. (2002). Attitudes Affecting College Students' Preferences for Distance Learning.

Keegan, D. (2002). The Future of Learning: From e-learning to m-learning. Retrieved from

Marinoni, G., Van't Land, H., \& Jensen, T. (2020). The impact of Covid-19 on higher education around the world. IAU Global Survey Report.

Moore, M. G. \& Kearsley.G. (2005). Distance Education: A Systems View (2nd ed.).

Nkingwa, D.M.M. (2013). Barriers to Effective Communication in Distance Education:

or Finding a Better Future? Online learning news,

Piskurich, G. M. (Ed.) (2003). Preparing Learners for e-Learning. San Francisco,

Samaraee, A. A. (2020). The impact of the COVID-19 pandemic on medical education.

Skills, Roles, and Responsibilities, Computer Assisted Language Learning, 22:1, 73-99, DOI: 10.1080/09588220802613831. Submitted in Partial Fulfillment of the requirement for the degree of Master of Teach Languages Online. Computer Assisted Language Learning 18 (4), 311-326.

Technology. International Journal of Social Science and Humanity, Vol. 5, No. 11.

Tele teaching 98: Distance Learning, Training, and Education: 569578.Austrian

Trentin, G. (1997). Telematics and Online Teacher Training: the Polaris project.

U.S.A.: Pfeiffer.

White, C. (2007). Innovation and Identity in Distance Language Learning and Teaching.

Williams, M. L., Paprock, K., \& Covington, B. (1998). Distance Learning: The Essential

World Conference on Online Learning Teaching in the Digital Age. Canada: www.onlinelearning.ca. 